\title{
Social Anxiety Disorder among Children at Gofermeda Sub City, Hosanna Town, Ethiopia: Prevalence and Associated Factors
}

\author{
Andualem Gebremichael Achiko, Ephrem Habte Shikuro* \\ Collage of Education and Behavioural Studies, School of Psychology, Jigjiga University, Jijiga, Ethiopia \\ Email: *efrisych@gmail.com, *ephrem.habte@jju.edu.et
}

How to cite this paper: Achiko, A. G., \& Shikuro, E. H. (2019). Social Anxiety Disorder among Children at Gofermeda Sub City, Hosanna Town, Ethiopia: Prevalence and Associated Factors. Psychology, 10, 1526-1541.

https://doi.org/10.4236/psych.2019.1011100

Received: June 3, 2019

Accepted: August 24, 2019

Published: August 27, 2019

Copyright $\odot 2019$ by author(s) and Scientific Research Publishing Inc. This work is licensed under the Creative Commons Attribution International License (CC BY 4.0).

http://creativecommons.org/licenses/by/4.0/

\begin{abstract}
Social anxiety disorder is a disabling anxiety disorder characterized by an extreme fear of unconstructive estimation in public situations. Human beings are social creatures. Accordingly, fear of social situations can be severely disabling. This study aimed at exploring the prevalence and factors associated with social anxiety disorder among children. The study employed cross-sectional descriptive survey. In this study $(n=300)$ out of 403 total population were selected randomly. Psychometric screening questionnaire administered and the association between social anxiety disorder with selected sociodemographic variables and victimization in children (aged 12 - 17) was investigated. Both descriptive and inferential statistics like, Frequencies distribution, univariate, bivariate and multivariate methods were used to analyse the collected data. In multivariate analysis, multiple linear regressions were used to see the predictive power of associated factors of social anxiety disorder. Besides, with these statistical method prevalence and the associated risk factors between demographic variables and victimization factors of social anxiety disorder were analysed. In this study, the prevalence of Self-reported social anxiety disorder among children was $63 \%$. From total sample of respondents $33 \%$ belongs age group below 15 years and the remaining $67 \%$ belongs age group above 15 years. This study indicated that, as the age of children increases prevalence of social anxiety disorder increases and in line with this, the higher prevalence of social anxiety disorder was found to be among children aged above 15 years. Females reported social anxiety disorder to a significantly higher degree than males in all age groups. Experiences of peer victimization, maltreatment and sexual victimization were also significantly related to social anxiety disorder. The study generally revealed, social anxiety disorder was associated with female gender, higher age group, low educational status, low income level of parent, experiences of peer victimization,
\end{abstract}


maltreatment and sexual victimization. We suggest that mental health service should be well organized and delivered accordingly and School counselling professionals, teachers and parents need to have a knowledge about social anxiety and effective interventions strategies has to be framed to help children and parents overcome social anxiety disorder.

\section{Keywords}

Social Anxiety Disorder, Children

\section{Introduction}

According to the fourth edition of the Diagnostic and Statistical Manual of Mental Disorders (DSM-IV), social anxiety disorder is defined as a marked and constant fear of one or more social and performance situations in which the individual is exposed to unfamiliar people. Thus, the central characteristic of social anxiety disorder is an intense fear of being observed by unfamiliar persons (APA, 2013). Social anxiety disorder is an enormously impairing disorder because children with social anxiety disorder is afraid of many everyday situations, such as eating and drinking in public, writing when someone is watching become near not possible challenges for the phobic children and or being in the centre of attention can be anxiety inducing for them (Essau, Conrad, \& Peterman, 1999). Social anxiety disorder in children is associated with low levels of adaptive functioning such as, emotional over responsiveness and loneliness, impairments in adaptive functioning, peer relations, self-esteem, school performance, social behaviour and psychosocial impairment (Strauss, Frame, \& Forehand, 1987).

Lots of areas of their life are affected for those who suffer from social anxiety disorder like wide use of alcohol and drugs in their future, as well as they suffer from marriage and employment difficulties in their future life, and academic underachievement (Amies, Gilder, \& Show, 1983). Also some of them are incapable to work, are at higher risk to be without a job, cannot work at their full ability, and lack career advancement in their later life. Some persons with social anxiety disorder are also at higher risk to be dependent on financial support and suffer from severe social limitation (Kessler, 2003).

In a study where 3211 Swedish high school students were screened for social anxiety disorder, self-reported social anxiety disorder was associated with early time victimization to a significantly higher degree, than it was in children who did not fulfil criteria for social anxiety disorder (Anderson \& Svedin, 2011). Also another study which was done in Swedish high school students indicated that a sample of 784 children with social anxiety disorder, two thirds (68\%) reported to have been bullied or victimized by their peer (Ranta, Kaltiale-Heino, Rantanen, \& Marttunen, 2009).

Although the etiology of social anxiety disorder in children is most likely multi-factorial, peer influences on the maintenance or even on onset of social 
anxiety disorder are likely to contribute (Parker, Rubin, Erath, Wojslawowicz, \& Buskirk, 2006). There are a variety of predictors of social anxiety disorders in children. These include various indices of social disadvantage such as low socioeconomic status, low educational status, family disruptions, parental non-employment, father's criminality, increased family size, overcrowding, and school disadvantage (Thabet \& Vostanis, 2000).

Again, most of the research which had been done on prevalence and predictors of social anxiety disorder among children has been undertaken in the West, with only a few exceptions (Muris, Merckelbach, De Jong, \& Ollendick, 2002). There is some evidence that social anxiety disorders in non-western countries have the same patterns as elsewhere, and may have similar predictors including age, gender, educational level and income level (Tadesse, Kebede, Tegen, \& Alem, 1999).

Although children constitute the majority of Ethiopian population, they do not get proper mental health care and of receiving proper attention from mental health care workers or other social sector is minimal (UNICEF, 1989). In spite of the importance given to mental health by the world health organization it has so far received relatively inadequate attention, especially in developing countries (APA, 2003). Besides, Poverty, economic crisis, child labour, life on street and migration to urban areas may predispose children not only to physical illness, but also to emotional disorders such as social anxiety disorder and depression in the developing world (UNICEF, 1989). Moreover, there are evidences which indicate that child maltreatment and child labour are increasing among children (UNICEF, 1989). All the above circumstances predispose children to a higher risk of developing psychiatric problems such as social anxiety disorder.

According to (Alem, Desta, \& Araya, 1995), the low level of children mental health care in Ethiopia is evidenced by: 1) insufficient or lacking of mental health services available for children, 2) inadequate treatment of the subject in curricula of health professionals training program, 3) the few number of community based studies about the extent and determinants of mental disorders, such as social anxiety disorder and 4) the negative attitude towards the mentally ill among community in general and the low priority given to child mental health care by policy makers in particular. This research report has also described poor access of research that had been done regarding to the prevalence and factors associated with social anxiety disorder, poor access to mental health treatment services and shortage of mental health professionals in the country as main causes for poor mental health of children.

A world collaborative team conducted a study to measure the prevalence of mental disorder including social anxiety disorder in 952 children attending primary health care in four developing countries. It was reported that the prevalence rate of mental disorders was $12 \%$ in Sudan, $15 \%$ in Philippines, $24 \%$ in India, and 24\% in Colombia (Giel et al., 1981).

In Ethiopia, there are few community based studies conducted on the preva- 
lence of mental disorders. Previous studies have also focused on general mental disorders; no studies have attempted to estimate or assess the prevalence and associated factors of specific types of mental disorders, such as social anxiety disorder. Thus, this study is intended to find out the prevalence and associated factors of social anxiety disorder among children. Hence, the study tried to answer; what the prevalence of social anxiety disorder among children, weather there is significant association among social anxiety disorder, socio-demographic characteristics and victimization of children.

Therefore, in this paper the term "child" or "children" is used to mean anyone under age of 18 , entitled to the rights proclaimed in the UN convention on the rights of child, including the right to get any access (UNICEF, 2005).

\section{Methods}

\subsection{Study Design and Area}

This study was used across-sectional descriptive survey to explore the prevalence of social anxiety disorder and its association with socio-demographic, socioeconomic characteristics and victimization. To obtain relevant information required for the study, Children aged 12 - 17 were chosen from two kebeles of Gofermeda sub city (Lecha and Melbera kebeles) Ethiopia.

\subsection{Inclusion and Exclusion Criteria}

Children were selected based on the following inclusion/exclusion criteria. The inclusion criteria included children who were: 1) aged 12 - 17,2) willing and able to give their consent, 3) had no major other psychiatric disorder, 4) had no significant sensory and/or language impairments and 5) did not participate in the pilot study. On the other hand, participants those who did not met the inclusion criteria were automatically excluded.

\subsection{Dependent Variable}

The dependent variable in this study was social anxiety disorder. It is a marked and persistent fear of one or more social or performance situations in which the person is exposed to unfamiliar people or possible scrutiny by others.

\subsection{Independent Variables}

The independent variables were selected socio-demographic characteristics such as age, gender, and educational level, income level of house hold, and victimization such as maltreatment, peer victimization/bullying, sexual victimization and witnessing victimization.

\subsection{Sampling and Participants}

The participants of the study were selected by using lottery method of random sampling technique. Out of total of 403 children, 300 who fulfilled the inclusion criteria were selected. One hundred seventy, 170 (59.66\%) were male and the 
remaining one hundred thirty, $130(43.33 .37 \%)$ were female.

\subsection{Instrument of Data Collection}

The Screen for Child Anxiety Related Emotional Disorders (SCARED), the sociodemographic Questionnaire and the Juvenile Victimization Questionnaire (JVQ) was administered for the assessment of participant's social anxiety disorder. The closed-ended questionnaire was developed to gather information about sociodemographic variables and victimization of participants. It has 41 questions focused on different social aspects, psychological aspects and related background information of participants.

The SCARED is a modified version of the Screen for Child Anxiety Related emotion Disorders (SCARED) was originally developed in English for a clinical population (Birmaher, Khetarpal, Brent, Cully, Balach, Kaufman, \& Neer, 1997). However, translated versions have been found to be reliable instruments to assess anxiety symptoms in other countries and have been used (Hale, Raaijmakers, Muris, \& Meeus, 2005). This was the case in the present study.

The SCARED was developed by Barmier and his collaborators. It comprises 41 items that can be grouped in to five sub scales. Four of these sub scales measures anxiety disorders symptoms as conceptualized in the DSM-IV-TR: social anxiety disorder, panic disorder, generalized anxiety disorder and separation anxiety disorder. The fifth sub scale, school anxiety, represents a common anxiety problem in childhood (Birmaher, Khetarpal, Brent, Cully, Balach, Kaufman, \& Neer, 1997). Of which the SCARED consists of 8 items regarding, to SAD based on the DSM-IV diagnostic criteria of SAD (APA, 1994).

The overall Alpha Cronbach's statistics was derived to be 0.628 and none of six items do not increase the overall alpha Cronbach value if they are removed. These items were be used to compute a variable representing children's SAD.

The Juvenile Victimization Questionnaire (Hamby, Finkelhor, Ormrod, \& Turner, 2004) measures offenses against young people and is in part built on American legal and insurance issues. It is designed as an interview but can be used in a self-administered format from the age of 12 - 17 years, which was the case in the present study. The self-administered format has proven to have good test-retest reliability and construct validity (Bittner, Egger, Erkanli, Jane, Foly, \& Angold, 2007). A version of the JVQ that investigates victimization during the prior year or six months and victimization was used in the present study. The 16 items in the present study cover four domains, described as maltreatment, victimization from peers or siblings, sexual victimization, and witnessing victimization. Its internal consistency, assessed by means of Cranach's Alpha, as well as good test-retest reliability (Bittner, Egger, Erkanli, Jane, Foly, \& Angold, 2007).

\subsection{Socio-Demographic Questionnaires}

Different socio-demographic characteristics were examined for their association with the prevalence of social anxiety disorder. These included sex, age, house- 
hold income, educational level of parent, and, area of residence and family functioning. Socio-demographic questionnaires which are included in this paper used to mean social situations of respondents. In this study 9 socio-demographic questionnaires were used to measure the prevalence of social anxiety disorder in children.

\subsection{Methods of Data Analysis}

Quantitative data analysis was used by using SPSS.20 and Univariate, bivariate, and multivariate statistical analysis methods were used. Both descriptive and inertial statistics were used. At Univariate stage, frequencies and cross tabulations was used to see prevalence and the associated risk factors between demographic and victimization factors of social anxiety disorder. In multivariate analysis, multiple and linear regressions were used to see the association between sociodemographic and victimization to social anxiety.

\section{Results}

This section focuses on the results intended to answer the three basic research objectives indicated so far in this paper.

According to Table 1, children of age group > 15 accounted for $66.9 \%$, of which $68.0 \%$ male and $65.4 \%$ were female respondents and the remaining $33.1 \%$ are comprised in age group $<15$ of sample population, of which $32 \%$ and $34.6 \%$ are male and female respondents respectively. With regard to the current educational status of respondents, $69.6 \%$ of respondents currently attending their formal school, about $30.4 \%$ never attended any formal school. The level of dropped out from the school is higher in females than males. $13.7 \%$ of respondents dropped their school to get job. $12.0 \%$ said that they dropped out the school to help their family. Concerning to the marital status of the parents, $95.0 \%$ said that they were living together with their parents of which $16.7 \%$ reported their parents were divorced, $8.3 \%$ was separated and $75.0 \%$ were widowed.

As it is indicated in Table 2, many of the sample respondents $(53.3 \%)$ reported that their parent's monthly income ranging between 200 - 500 ETB. About 34\% have monthly income ranging between 501 - 800 ETB and about $3.8 \%$ have got income ranging between $801-1000$ ETB and $4.5 \%$ have got greater than $1000 \mathrm{ETB}$. Child respondents were asked about the educational level of their parents. According to the above table, it can be seen that significant percentage of parents of children respondents which is $6.7 \%$ attended only secondary school while $39.8 \%$ have primary school which is the highest followed by $29.1 \%$ literate parents and $23.4 \%$ illiterates. The above data indicated that majority of child respondents were from low educational status parents.

As it is shown in Table 3, percent of the male and female children who has moderately experienced social anxiety disorder (SAD) were about $35 \%$ and $44 \%$ respectively. Similarly the percent of male and female children who has severely experienced social anxiety disorder (SAD) were about $18 \%$ and $32 \%$ respectively. 
Table 1. Socio-demographic characteristics of the children respondents $(n=300)$.

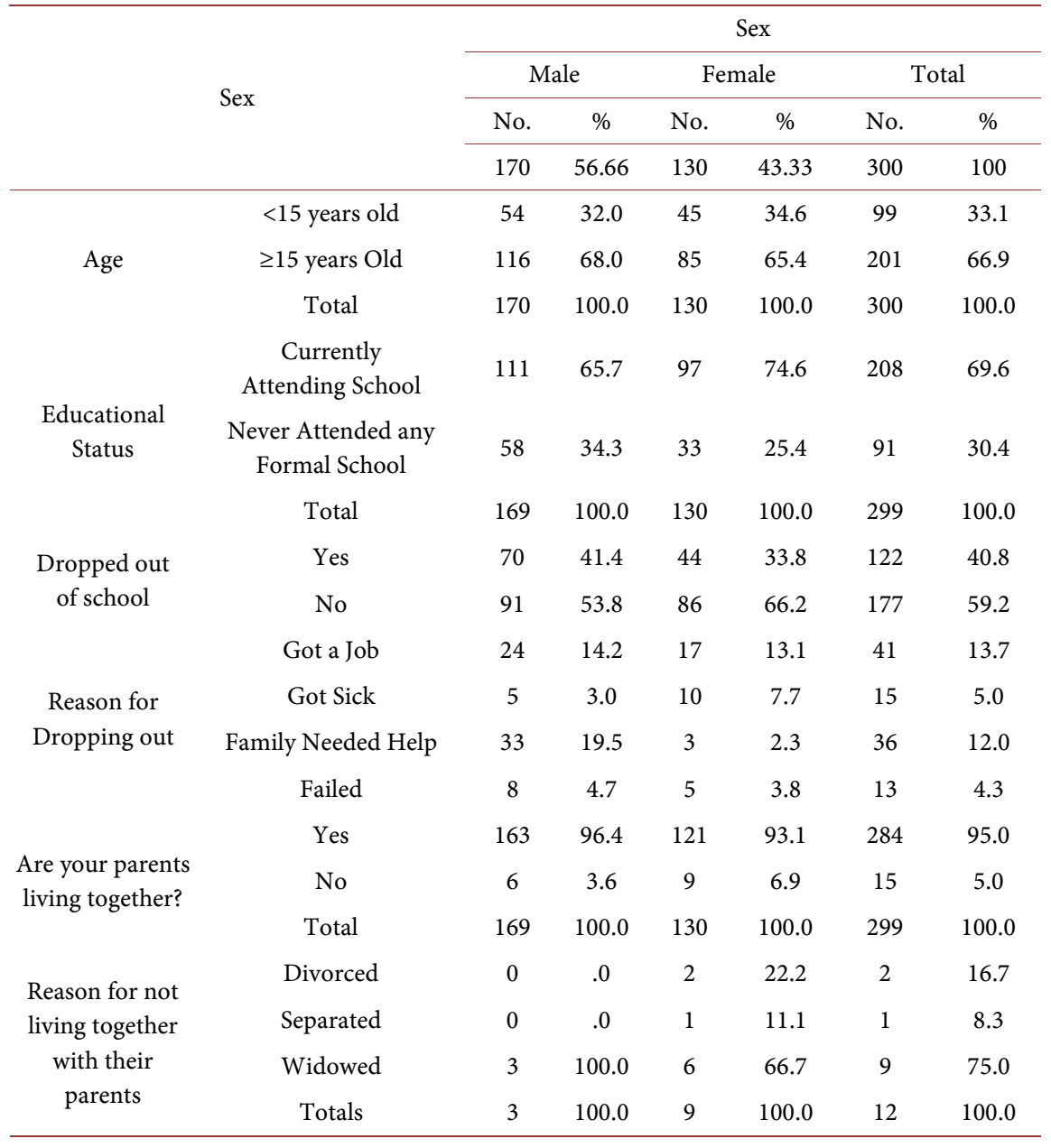

Table 2. Socioeconomic status of the parents of the sample children.

\begin{tabular}{cccccccc}
\hline & & \multicolumn{3}{c}{ Sex } \\
\cline { 3 - 8 } & & \multicolumn{2}{c}{ Male } & \multicolumn{2}{c}{ Female } & \multicolumn{2}{c}{ Total } \\
\cline { 3 - 8 } & & No. & $\%$ & No. & $\%$ & No. & $\%$ \\
\hline \multirow{4}{*}{$\begin{array}{c}\text { Educational } \\
\text { Status of your }\end{array}$} & Literate but not formal & 44 & 26.0 & 43 & 33.1 & 87 & 29.1 \\
parents & Primary $(1-8)$ & 70 & 41.4 & 49 & 37.7 & 119 & 39.8 \\
& Secondary (9 - 12) & 10 & 5.9 & 10 & 7.7 & 20 & 6.7 \\
& Tertiary (12+) & 2 & 1.2 & 1 & .8 & 3 & 1.0 \\
& Total & 169 & 100.0 & 130 & 100.0 & 299 & 100.0 \\
& Under 200 ETB & 6 & 3.8 & 6 & 4.6 & 12 & 4.2 \\
Monthly income & $200-500$ ETB & 79 & 50.3 & 73 & 56.2 & 152 & 53.0 \\
of your parents & $501-800$ ETB & 61 & 38.9 & 38 & 29.2 & 99 & 34.5 \\
& $801-1000$ ETB & 6 & 3.8 & 5 & 3.8 & 11 & 3.8 \\
& $>1000$ ETB & 5 & 3.2 & 8 & 6.2 & 13 & 4.5 \\
& Total & 157 & 100.0 & 130 & 100.0 & 287 & 100.0 \\
\hline
\end{tabular}

ETB is an abbreviation for Ethiopian Birr. 
Table 3. Prevalence of social anxiety disorder in the sample children.

\begin{tabular}{ccccccccc}
\hline & & \multicolumn{9}{c}{ Sex } \\
\cline { 3 - 8 } & & \multicolumn{2}{c}{ Male } & \multicolumn{2}{c}{ Female } & \multicolumn{2}{c}{ Total } \\
\cline { 3 - 8 } & Almost no SAD & 79 & 46.7 & 31 & 23.8 & 110 & 36.8 \\
\hline \multirow{2}{*}{$\begin{array}{c}\text { Prevalence of } \\
\text { social anxiety } \\
\begin{array}{c}\text { disorder in } \\
\text { children }\end{array}\end{array}$} & Moderate SAD & 59 & 34.9 & 57 & 43.8 & 116 & 38.8 \\
& Severe SAD & 31 & 18.3 & 42 & 32.3 & 73 & 24.4 \\
\hline
\end{tabular}

Regardless of the sex difference, about $39 \%$ and $24 \%$ of children experienced moderate and severe social anxiety disorder (SAD) respectively. This is to mean that about $63 \%$ of children experienced social anxiety disorder (SAD). Therefore, the overall prevalence of social anxiety disorder among children in the study found to be $63 \%$. Moreover, the prevalence of social anxiety disorder was high in females than males.

As indicated above, a multiple linear regression model was fit for children's SAD against the independent dummy variables (sex, marital status of parents, educational enrolment of the child, educational and income, status of parents) and continuous variables (age, maltreatment, peer and sibling's victimization, sexual victimization and witnessed victimization). The overall regression model is found to be strongly significant with coefficient of determination $\left(\mathrm{R}^{2}\right)=0.517$. As it is presented in Table 4, most of the variables predicted children's social anxiety disorder significantly with error level less than 0.05 .

As the linear regression model showed regarding socio-demographic factors; sex, age, income of parents, educational status of parents are strongly associated with social anxiety disorder. For example, being female sex is more likely for the presence of social anxiety disorder than the male counterpart. As age of children increases social anxiety disorder also increases. Regarding to educational enrolment, children who have not enrolled has higher social anxiety disorder and children who have enrolled have decreased social anxiety disorder. The prevalence of social anxiety disorder was high among children from parents of low education and low income level. Besides, high income level decreases the presence of social anxiety disorder in children.

However, in this study, no significance association found between drop out of children and the marital status of parents with social anxiety disorder. As the regression model showed regarding to victimization, children who has been maltreated by their family have high social anxiety disorder and children who have treated well by their family have not experienced social anxiety disorder relatively. The more children victimized sexually, by peer and witnesses the higher they develop social anxiety disorder. Similarly children who have not victimized by their peer, sexually, and by witness experience decreased social anxiety disorder. 
Table 4. The predictors of children's social anxiety disorder.

\begin{tabular}{|c|c|c|c|c|c|c|}
\hline \multicolumn{7}{|c|}{ Dependent Variable: Children's Feeling about their social anxiety disorder } \\
\hline \multirow[b]{2}{*}{ Parameter } & \multirow[b]{2}{*}{ B } & \multirow[b]{2}{*}{ Std. Error } & \multirow[b]{2}{*}{$\mathrm{T}$} & \multirow[b]{2}{*}{ Sig. } & \multicolumn{2}{|c|}{ 95\% Confidence Interval } \\
\hline & & & & & $\begin{array}{l}\text { Lower } \\
\text { Bound }\end{array}$ & $\begin{array}{l}\text { Upper } \\
\text { Bound }\end{array}$ \\
\hline Intercept & -0.198 & 0.626 & -0.316 & 0.752 & -1.431 & 1.035 \\
\hline Sex & -0.348 & 0.050 & -0.934 & 0.000 & -0.446 & -0.249 \\
\hline Education enrolled & -0.178 & 0.072 & -2469 & 0.014 & -0.319 & -0.036 \\
\hline Drop out & 0.026 & 0.043 & 0.605 & 0.546 & -0.059 & 0.111 \\
\hline Parents living together & 0.065 & 0.088 & 0.732 & 0.465 & -0.109 & 0.239 \\
\hline Education of parents & 0.121 & 0.236 & 0.515 & 0.607 & -0.343 & 0.585 \\
\hline $\begin{array}{l}\text { Education of parent literate but } \\
\text { without formal education }\end{array}$ & 0.216 & 0.232 & 0.931 & 0.353 & -0.241 & 0.673 \\
\hline Education of parents Primary & -0.115 & 0.233 & -0.495 & 0.621 & -0.573 & 0.343 \\
\hline Education of parents Secondary & 0.068 & 0.254 & 0.268 & 0.789 & -0.432 & 0.568 \\
\hline Income of parents $<200$ & 0.000543 & 0.129 & 0.000 & 1.000 & -0.254 & 0.254 \\
\hline Income of parents $201-500$ & -0.208 & 0.098 & -2.122 & 0.035 & -0.401 & -0.015 \\
\hline Income of parents $501-800$ & 0.064 & 0.116 & 0.550 & 0.582 & -0.164 & 0.292 \\
\hline Income of parents $801-1000$ & -0.081 & 0.133 & -0.612 & 0.541 & -0.344 & 0.181 \\
\hline Age & 0.150 & 0.021 & 7.035 & 0.000 & 0.108 & 0.192 \\
\hline Maltreatment & -0.463 & 0.089 & -5.185 & 0.000 & -0.638 & -0.287 \\
\hline Peer or sibling victimization & -0.437 & 0.138 & -3.168 & 0.002 & -0.708 & -0.165 \\
\hline Sexual victimization & 0.317 & 0.158 & 2.001 & 0.046 & 0.005 & 0.628 \\
\hline Witness victimization & -0.070 & 0.151 & -0.462 & 0.644 & -0.366 & 0.227 \\
\hline
\end{tabular}

\section{Discussion}

The present study showed that social anxiety disorder (SAD) is commonly reported by children age of $12-17$ years. From the total sample children, about $38.8 \%$ and $24.4 \%$ of the children experienced moderate and sever social anxiety disorder respectively. The overall prevalence of social anxiety disorder was found to be $63 \%$. From this study, it's been observed that high rate social anxiety disorder in children is in the school-domain and is affecting leisure time activities of school children. Therefore, social anxiety disorder should be considered as a condition to be taken seriously. Social anxiety disorder implies avoidance of restricted situations which is certainly not the case for most children with social anxiety disorder as feared stimuli involve a wide range of situations in life. Among children with social anxiety disorder, the majority reported marked fear of speaking in front of their peer. These findings also indicated that, parents be likely not aware of social fear and associated suffering of their child; which means they were not well-informed on how social anxiety disorder presents, associated with impairment and that social anxiety disorder is not the same with 
non-problematic shyness.

Consistently to the present study, higher rates of fears and phobias and an increased risk of social anxiety disorder in girls compared to boys are reported (Canino, Shrout, Rubio-Stipec, Bird, Bravo, Ramirez, Chaves, Alegria, Bauermeister, Hohmann, Ribera, Garcia, \& Martinez-Taboas, 2004). Similarly another study also revealed the same (Lewinsohn, Gotlib, Lewinsohn, Seely, \& Allen, 1998). There is a difference between boys and girls in developing social anxiety disorder. Almost at all age levels (12 - 17) females were high in experiencing social anxiety disorder. In contrary to this finding other finding indicated that no differences between boys and girls have been reported in young Children with symptoms of social anxiety (Weeks, Coplan, \& Kingsbury, 2009). A finding supports this study indicated sex differences in prevalence of SAD around age 13 (Bittner, Egger, Erkanli, Jane, Foly, \& Angold, 2007; Van Roy, Kristensen, Groholt, \& Clench-Aas, 2009) with more girls than boys reporting SAD (Canino, Shrout, Rubio-Stipec, Bird, Bravo, Ramirez, Chaves, Alegria, Bauermeister, Hohmann, Ribera, Garcia, \& Martinez-Taboas, 2004). Differences between males and females may be limited to fear of certain social situations. For example, when investigating sex differences closer, it was found that only fear of "doing something in front of others" was more common in females than in male (Essau, Conrad, \& Peterman, 1999). A similar result was found by Sumter and his colleagues (Sumter, Bokhorst, \& Westenberg, 2009). However, in the study of Wittchen and his colleagues (Wittchen, Nelson, \& Kessler, 1999) higher rates were found in females on all measured social fear situations. So the finding of this study supports the above idea which means females experience more social anxiety of doing something's in front of others.

As this study indicated, the higher the age, the increased SAD they experience. In this way, concern about physical appearance and others' opinions, may explain the greater fear in females side for doing something in front of others. Supportive to this stud, the development of self-consciousness is suggested to be one condition related to the onset of SAD and self-consciousness is reported to be more pronounced in girls (La Greca \& Lopez, 1998). The above indicated idea is one possible explanation of higher rates of social fear in girls.

In studies on children and adolescents, an association with puberty and hormonal changes was found in girls with anxiety symptoms (Altemus, 2006; Angold, Costello, Erkanli, \& Worth Man, 1999). Social anxiety and puberty onset was studied in one cross-sectional study which found that advanced pubertal development was associated with heightened levels of social anxiety in girls but not in boys (Deardorff, Hayward, Wilson, Bryson, Hammer, \& Agras, 2007). Another study showed an association between pubertal status and timing and social anxiety both in boys and girls aged 10 - 12 (Ge, Brody, Conger, \& Simons, 2006). Early physical development can lead to unwanted sexual attention and body dissatisfaction where girls are more prone to negative self-evaluation and being more sensitive to others' opinions regarding appearance and behaviour, as 
mentioned earlier. The role of hormones and other biological factors in the etiology of SAD remains to be studied further. The increasing rate of internalizing disorders in girls during adolescence has also been linked to interpersonal stress which becomes more pronounced during adolescence (Nolen-Hoeksema \& Girgus, 1994). Girls are more oriented towards interpersonal goals like connection and perceive negative experiences in these domains as more stressing than boys do (Hayward \& Sanborn, 2002; Rose \& Rudolph, 2006; Rudolph, 2002).

As this study indicated the higher rates of self-reported social anxiety disorder were seen in children with low educational status and low income level of parents. Income level and educational background of the parents highly affects children to develop social anxiety disorder. Different findings indicated that children and adolescence having low socio-economic status and low educational status are more likely than to develop anxiety disorders. This study also indicated, most children belonging from low income status of parents and low educational status of parents attributed for children to develop social anxiety disorder. The prevalence of social anxiety disorder is highly correlated and associated with low income level and low educational background. Epidemiological studies on adults show that SAD is associated with low income levels, lower educational attainment and being unmarried (Furmark, 2002).

Concerning other demographic factors, inconsistently with this study, parent's marital status and school dropout were not significantly associated with social anxiety disorder. Here we recommend other researchers to consider larger number of sample than this study while studying social anxiety among children. Sex, age, low economic background, and low educational background seem to be clearly related to higher rates of SAD in children.

Regarding associated factors, the present study indicated that, victimization has been one factor for social anxiety disorder among children and again results from the study on range of victimizing events and self-reported social anxiety disorder in older children ( $>15$ years) were reported. An association between victimization and social anxiety disorder was found, with higher rates of victimization in children with social anxiety disorder. Particularly, experiences of, victimization from peers/bullying (40\%), maltreatment (76\%), sexual victimization $(27.8 \%)$, and witness victimization (29\%) were more common in children reporting social anxiety disorder. It should be noted that the present study concluded that there is a contributory relationship between social anxiety disorder and victimization. Maltreatment was significant indicator of social anxiety disorder. As this study indicated $76 \%$ of respondents were seriously maltreated by their family which means they were emotionally neglected, kicked and experienced parental fighting. Consistently to this finding, maltreatment was found to be associated with social anxiety disorder. In adults, emotional neglect has been reported as a significant predictor of incidence of social anxiety disorder (Ataturk, Smit, De Graaf, Van Straten, Ten Have, \& Cuijpers, 2009) and an association between maltreatment and severity of social anxiety disorder has been 
found (Simon, Heralds, Marks, Mancini, Letamendi, Li, Pollack, Van Ameringen, \& Stein, 2009).

Moreover, consistently with this study, maltreatment have been reported in studies on victimization and social anxiety disorder in children and adolescents. Understanding of the association between maltreatment and social anxiety disorder can be related to findings from a few studies on information processing in maltreated children (Hadwin, Garner, \& Perez-Olives, 2006). A significant association was found between peer victimization and social anxiety disorder. In this study, $54.9 \%$ said they were seriously victimized by their peer about $53.8 \%$ moderately victimized by their peer. The finding of this study showed that peer victimization has been as one predictor of social anxiety disorder among children. Supportive to this, other finding indicated the experiences of peer victimization are considered as a major health issue in children (Currie, Levin, Todd, \& HBSC National Team, 2008).

Supportive to this finding, victimization by peers may be interpreted as a lack of approval from others (Boivin, Hymel, \& Bukowski, 1995) and the characteristics of social anxiety is a negative expectation of being negatively evaluated by others (APA, 1994). This is feelings of worthlessness and loneliness involved in social anxiety disorder (Stein, Fuetsch, Muller, Hofler, Lieb, \& Wittchen, 2001). The present study supports the above indicated idea and being victimized by peer in school, home or elsewhere was significantly associated with social anxiety disorder. As the result of this study indicated, significant association was found between witness victimization and social anxiety disorder. However, the association between being victimized by witness and social anxiety disorder was not found significant. In present study sexual victimization was found to be associated with social anxiety disorder. Sexual abuse is less common in males than in females (Finkelhor, 1994). Consistently, the present study rates of sexual victimization were high in females than in male.

\section{Conclusion}

Social anxiety disorder is more common in female than in male children and also in those with parents of lower educational levels, and low economic levels. Social anxiety disorder is more among children maltreated by their family, experienced sexual and peer victimization, whereas marriage status and witness victimization have relatively little association. Most children reported impairment in the school-domain and leisure activities due to their fear of public situations and impairment in performance situation due to their fear of performing their task in front of others. Besides, social anxiety disorder increases when the age of children increases over one stage to another stage. Social anxiety disorder is highly prevalent under the age level of 15 - 17 years and it increases as the age of children increases. The self-reported Social anxiety disorder in older children was associated with reports of victimization, especially peer victimization and maltreatment and sexual victimization. 


\section{Acknowledgements}

The authors would like to thank the study participants for their genuine responses. In addition, our deepest gratitude goes to of Hosana, Ethiopia, Gofermeda sub city lecha and Melbera kebele administrators and other data collection team for their kind collaboration.

\section{Conflicts of Interest}

The authors declare no conflicts of interest regarding the publication of this paper.

\section{References}

Alem, A., Desta, M., \& Araya, M. (1995). Mental Health in Ethiopia. Ethiopian Journal of Health Development, 9, 47-62.

Altemus, M. (2006). Sex Differences in Depression and Anxiety Disorders: Potential Biological Determinants. Hormones and Behavior, 50, 534-544.

Amies, P. L., Gilder, M. G., \& Shaw, P. M. (1983). Social Phobia: A Comparative Clinical Study. British Journal of Psychiatry, 142, 174-179. https://doi.org/10.1192/bjp.142.2.174

Anderson, J. C., \& Svedin, P. A. (2011). DSM-III Disorders in Preadolescent Children: Prevalence in a Large Sample from the General Population. Archives of General Psychiatry, 28, 842-846.

Angold, A., Costello, E. J., Erkanli, A., \& Worth Man, C. M. (1999). Pubertal Changes in Hormone Levels and Depression in Girls. Psychological Medicine, 29, 1043-1053. https://doi.org/10.1017/S0033291799008946

APA (American Psychiatric Association) (1994). Diagnostic and Statistical Manual of Mental Disorders (4th ed.). Washington DC: APA.

APA (American Psychiatric Association) (2003). Diagnostic and Statistical Manual of Mental Disorders (4th ed.). Washington DC: APA.

APA (American Psychiatric Association) (2013). Diagnostic and Statistical Manual of Mental Disorders (5th ed.). Washington DC: APA. https://doi.org/10.1176/appi.books.9780890425596

Ataturk, C., Smit, F., de Graaf, R., van Straten, A., ten Have, M., \& Cuijpers, P. (2009). Incidence of Social Phobia and Identification of Its Risk Indicators: A Model for Prevention. Acta Psychiatrica Scandinavica, 119, 62-70. https://doi.org/10.1111/j.1600-0447.2008.01275.x

Birmaher, B., Khetarpal, S., Brent, D., Cully, M., Balach, L., Kaufman, J., \& Neer, S. M. (1997). The Screen for Chid Anxiety Related Emotional Disorders (SCARED): Scale Construction and Psychometric Characteristics. Journal of the American Academy of Child and Adolescent Psychiatry, 36, 545-553. https://doi.org/10.1097/00004583-199704000-00018

Bittner, A., Egger, H. L., Erkanli, A., Jane Costello, E., Foley, D. L., \& Angold, A. (2007). What Do Childhood Anxiety Disorders Predict? Journal of Child Psychology and Psychiatry, and Allied Disciplines, 48, 1174-1183. https://doi.org/10.1111/j.1469-7610.2007.01812.x

Boivin, M., Hymel, S., \& Bukowski, W. M. (1995). The Roles of Social Withdrawal, Peer Rejection, and Victimization by Peers in Predicting Loneliness and Depressed Mood in Children. Development and Psychopathology, 7, 765-786. 
https://doi.org/10.1017/S0954579400006830

Canino, G., Shrout, P., Rubio-Stipec, M., Bird, H., Bravo, M., Ramírez, R., Chavez, L., Alegría, M., Bauermeister, J. J., Hohmann, A., Ribera, J., García, P., \& Martínez-Taboas, A. (2004). The DSM-IV Rates of Child and Adolescent Disorders in Puerto Rico: Prevalence, Correlates, Service Use, and the Effects of Impairment. Archives of General Psychiatry, 61, 85-93. https://doi.org/10.1001/archpsyc.61.1.85

Currie, C. E., Levin, K. A., Todd, J., \& HBSC National Team (2008). Health Behaviour in School-Aged Children: World Health Organization Collaborative Cross-National Study (HBSC): Findings from the 2006 HBSC Survey in Scotland. HBSC Scotland National Report. Edinburgh: Child and Adolescent Health Research Unit (CAHRU).

Deardorff, J., Hayward, C., Wilson, K. A., Bryson, S., Hammer, L. D., \& Agras, S. (2007). Puberty and Gender Interact to Predict Social Anxiety Symptoms in Early Adolescence. Journal of Adolescent Health, 41, 102-104. https://doi.org/10.1016/j.jadohealth.2007.02.013

Essau, C, A., Conrad, J., \& Peterman, F. (1999). Frequency and Comorbidity of Social Phobia and Social Fears in Children. Behavior Research and Therapy, 37, 831-843.

Finkelhor, D. (1994). The International Epidemiology of Child Sexual Abuse. Child Abuse and Neglect, 18, 409-417. https://doi.org/10.1016/0145-2134(94)90026-4

Furmark, T. (2002). Social Phobia: Overview of Community Surveys. Acta Psychiatrica Scandinavica, 105, 84-93. https://doi.org/10.1034/j.1600-0447.2002.1r103.x

Ge, X., Brody, G. H., Conger, R. D., \& Simons, R. L. (2006). Pubertal Maturation and African American Children's Internalizing and Externalizing Symptoms. Journal of Youth and Adolescence, 35, 528-537. https://doi.org/10.1007/s10964-006-9046-5

Giel, R., de Arango, M. V., Climent, C. E., Harding, T. W., Ibrahim, H. H., Ladrido-Ignacio, L., Murthy, R. S., Salazar, M. C., Wig, N. N., \& Younis, Y. O. (1981). Childhood Mental Disorder in Primary Health Care: Result of Observation in Four Developing Countries. A Report from WHO Collaborative Study on Strategies for Extending Mental Health Care, 1981. Pediatrics, 68, 677-683.

Hadwin, J. A., Garner, M., \& Perez-Olives, G. (2006). The Development of Information Processing Biases in Childhood Anxiety: A Review and Exploration of Its Origins in Parenting. Clinical Psychology Review, 26, 876-894.

https://doi.org/10.1016/j.cpr.2005.09.004

Hale, W., Raaijmakers, Q., Muris, P., \& Meeus, W. (2005). Psychometric Properties of the Screen for Child Anxiety Related Emotional Disorders (Scared) in the General Adolescent Population. Journal of the American Academy of Child \& Adolescent Psychiatry, 44, 283-290. https://doi.org/10.1097/00004583-200503000-00013

Hamby, S. L., Finkelhor, D., Ormrod, R. K., \& Turner, H. A. (2004) The Juvenile Victimization Questionnaire (JVQ): Administration and Scoring Manual. Durham, NH: Crimes against Children Research Center. https://doi.org/10.1037/t01856-000

Hayward, C., \& Sanborn, K. (2002). Puberty and the Emergence of Gender Differences in Psychopathology. Journal of Adolescent Health, 30, 49-58. https://doi.org/10.1016/S1054-139X(02)00336-1

Kessler, R. C. (2003). The Impairments Caused by Social Phobia in the General Population: Implications for Intervention. Acta Psychiatric Scondinavica, 108, 19-27.

https://doi.org/10.1034/j.1600-0447.108.s417.2.x

La Greca, A., \& Lopez, N. (1998). Social Anxiety among Adolescents: Linkages with Peer Relations and Friendships. Journal of Abnormal Child Psychology, 26, 83-94. https://doi.org/10.1023/A:1022684520514 
Lewinsohn, P. M., Gotlib, I. H., Lewinsohn, M., Seely, J. R., \& Allen, N. B. (1998). Gender Difference in Anxiety Disorder and Anxiety Symptom in Adolescence. Journal of $A b$ normal Psychology, 107, 109-117. https://doi.org/10.1037//0021-843X.107.1.109

Muris, P., Merckelbach, H., de Jong, P. J., \& Ollendick, T. H. (2002). The Etiology of Specific Fears and Phobias in Children: A Critique of the Non-Associative Account. Behavior Research and Therapy, 40, 185-195. https://doi.org/10.1016/S0005-7967(01)00051-1

Nolen-Hoeksema, S., \& Girgus, J. S. (1994). The Emergence of Gender Differences in Depression during Adolescence. Psychological Bulletin, 115, 424-443. https://doi.org/10.1037/0033-2909.115.3.424

Parker, J. G., Rubin, K. H., Erath, S. A., Wojslawowicz, J. C. and Buskirk, A. A. (2006). Peer Relationships, Child Developmental Psychopathology Perspective. In Developmental Psychopathology (2nd ed., Vol. 1, pp. 419-493). Hoboken, NJ: Wiley. https://doi.org/10.1002/9780470939383.ch12

Ranta, K., Kaltiale-Heino, R., Rantanen, P., \& Marttunen, M. (2009). Social Phobia in Finnish General Adolescent Population: Prevalence, Comorbidity, Individual and Family Correlates, and Service Use. Depression and social Anxiety, 2, 528-536. https://doi.org/10.1002/da.20422

Rose, A. J., \& Rudolph, K. D. (2006). A Review of Sex Differences in Peer Relationship Processes: Potential Trade-Offs for the Emotional and Behavioral Development of Girls and Boys. Psychological Bulletin, 132, 98-131.

https://doi.org/10.1037/0033-2909.132.1.98

Rudolph, K. D. (2002). Gender Differences in Emotional Responses to Interpersonal Stress during Adolescence. Journal of Adolescent Health, 30, 3-13. https://doi.org/10.1016/S1054-139X(01)00383-4

Simon, N. M., Heralds, N. N., Marks, E. H., Mancini, C., Letamendi, A., Li, Z., Pollack, M. H., Van Ameringen, M., \& Stein, M. B. (2009). Childhood Maltreatment Linked to Greater Symptom Severity and Poorer Quality of Life and Function in Social Anxiety Disorder. Depression and Anxiety, 26, 1027-1032. https://doi.org/10.1002/da.20604

Stein, M., Fuetsch, M., Muller, N., Höfler, M., Lieb, S., \& Wittchen, H. U. (2001). Social Anxiety Disorder and the Risk of Depression. A Prospective Community Study of Adolescents and Young Adults. Archives of General Psychiatry, 58, 251-256. https://doi.org/10.1001/archpsyc.58.3.251

Strauss, C. C., Frame, C. L., \& Forehand, R. (1987). Psychosocial Impairment Associated with Anxiety in Children. Journal of Clinical Child Psychology, 16, 235-239. https://doi.org/10.1207/s15374424jccp1603_8

Sumter, S. R., Bokhorst, C. L., \& Westenberg, P. M. (2009). Social Fears during Adolescence: Is There an Increase in Distress and Avoidance? Journal of Anxiety Disorders, 23, 897-903. https://doi.org/10.1016/j.janxdis.2009.05.004

Tadesse, B., Kebede, D., Tegen, T., \& Alem, A. (1999). Child hood Behavioral Disorders in Ambo district, Western Ethiopia. Acta Psychiatrica Scandinavica, 397, 92-97.

Thabet, A., \& Vostanis, P. (2000). Child Mental Health Problems in Children. International Journal of Social Psychiatry, 46, 266-280. https://doi.org/10.1177/002076400004600404

UNICEF (1989). Children and Women in Ethiopia. A Situational Analysis. Addis Ababa, Etiopia.

UNICEF (2005). Child Poverty in Rich Countries. Report Card No. 6. Florence, Italy: UNICEF Innocenti Research Centre.

Van Roy, B., Kristensen, H., Groholt, B., \& Clench-Aas, J. (2009). Prevalence and Char- 
acteristics of Significant Social Anxiety in Children Aged 8-13 Years. Social Psychiatry and Psychiatric Epidemiology, 44, 407-415. https://doi.org/10.1007/s00127-008-0445-7

Weeks, M., Coplan, R. J., \& Kingsbury, A. (2009). The Correlates and Consequences of Early Appearing Social Anxiety in Young Children. Journal of Anxiety Disorders, 23, 965-972. https://doi.org/10.1016/j.janxdis.2009.06.006

Wittchen, H. U., Nelson, C. B., \& Kessler, R. C. (1999). Social fears and DSM-IV Social Phobia in a Community Sample of Adolescents and Young Adults: Prevalence, Risk Factors and Comorbidity. Psychological Medicine, 29, 309-329.

https://doi.org/10.1017/S0033291798008174 